2002s-56

\title{
Addressing Dynamism in E-negotiations by Workflow Management Systems
}

\author{
Sarita Bassil, Morad Benyoucef,
}

Rudolf K. Keller, Peter Kropf

Série Scientifique

Scientific Series

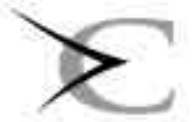

CIRANO

Montréal

Mai 2002 


\section{CIRANO}

Le CIRANO est un organisme sans but lucratif constitué en vertu de la Loi des compagnies du Québec. Le financement de son infrastructure et de ses activités de recherche provient des cotisations de ses organisationsmembres, d'une subvention d'infrastructure du ministère de la Recherche, de la Science et de la Technologie, de même que des subventions et mandats obtenus par ses équipes de recherche.

CIRANO is a private non-profit organization incorporated under the Québec Companies Act. Its infrastructure and research activities are funded through fees paid by member organizations, an infrastructure grant from the Ministère de la Recherche, de la Science et de la Technologie, and grants and research mandates obtained by its research teams.

\section{Les organisations-partenaires / The Partner Organizations}

-École des Hautes Études Commerciales

-École Polytechnique de Montréal

-Université Concordia

-Université de Montréal

-Université du Québec à Montréal

-Université Laval

-Université McGill

-Ministère des Finances du Québec

-MRST

-Alcan inc.

- AXA Canada

-Banque du Canada

-Banque Laurentienne du Canada

- Banque Nationale du Canada

- Banque Royale du Canada

- Bell Canada

- Bombardier

- Bourse de Montréal

-Développement des ressources humaines Canada (DRHC)

-Fédération des caisses Desjardins du Québec

-Hydro-Québec

-Industrie Canada

-Pratt \& Whitney Canada Inc.

-Raymond Chabot Grant Thornton

-Ville de Montréal

(C) 2002 Sarita Bassil, Morad Benyoucef, Rudolf K. Keller et Peter Kropf. Tous droits réservés. All rights reserved. Reproduction partielle permise avec citation du document source, incluant la notice (C).

Short sections may be quoted without explicit permission, if full credit, including (C) notice, is given to the source.

Les cahiers de la série scientifique $(\mathrm{CS})$ visent à rendre accessibles des résultats de recherche effectuée au CIRANO afin de susciter échanges et commentaires. Ces cahiers sont écrits dans le style des publications scientifiques. Les idées et les opinions émises sont sous l'unique responsabilité des auteurs et ne représentent pas nécessairement les positions du CIRANO ou de ses partenaires.

This paper presents research carried out at CIRANO and aims at encouraging discussion and comment.

The observations and viewpoints expressed are the sole responsibility of the authors. They do not necessarily represent positions of CIRANO or its partners.

\section{ISSN 1198-8177}




\title{
Addressing Dynamism in E-negotiations by Workflow Management Systems*
}

\author{
Sarita Bassil ${ }^{\dagger}$, Morad Benyoucef ${ }^{*}$, Rudolf K. Keller ${ }^{\S}$, and Peter Kropf ${ }^{* * 1}$
}

\section{Résumé / Abstract}

La technologie des Workflows (Wfs) s'est avérée importante pour le commerce électronique. Dans le cadre de notre recherche, une négociation combinée $(\mathrm{CN})$ est modélisée et exécutée utilisant un Wf. La phase de modélisation capture la séquence des différentes négociations ainsi que les dépendances qui existent entre elles. La phase d'exécution quant à elle, permet comme son nom l'indique, d'exécuter le modèle. Un système de support pour les CN (CONSENSUS) est utilisé pour accomplir ces deux tâches. Supporter les modifications dynamiques du modèle lors de l'exécution devrait augmenter les bénéfices de notre approche. Dans cet article, nous mettons l'emphase sur le besoin d'un tel support, ceci en identifiant les aspects dynamiques qui peuvent apparaître lors de la négociation des différents items d'un package (i.e., l'objet de la CN). Nous utilisons ADEPT - un système de gestion de Wf qui supporte le dynamisme - pour étudier ces aspects. Ceci nous mène à discuter le modèle de référence de la Wf Management Coalition, et à proposer une extension "dynamique" à l'architecture actuelle.

Workflows (Wfs) are a major enabling technology for e-commerce. In our research, a Combined Negotiation (CN) is modeled and enacted using Wf technology. The modeling task captures the sequencing of the individual negotiations as well as the dependencies between them, and the enacting task runs the model. A CN support system (CONSENSUS) is used by the user to perform both tasks. Supporting dynamic modifications to the model during runtime should increase the benefits of our approach. In this paper, we highlight the need for such support by identifying the dynamic aspects that can occur while negotiating the different items of a package (i.e., the CN object). To address these aspects, we experimented using ADEPT, a Wf Management System supporting dynamism. This leads us to discuss the Wf Reference Model of the Wf Management Coalition, and suggest a "dynamic" extension to the current functional areas and architecture.

Mots-clés : Négociations électroniques, Approvisionnement, Workflows, Systèmes de gestion de Workflow, Dynamisme

Keywords: e-Negotiations, Sourcing, Workflows, Workflow management systems, Dynamism

\footnotetext{
* The completion of this research was made possible thanks to funding provided by the NSERC (CRD-224950-99), Bell Canada's support through its Bell University Laboratories R\&D program, and support by the CIRANO.

† CIRANO and Département IRO, Université de Montréal, C.P. 6128, succursale Centreville,Montréal, Québec, H3C 3J7, Canada. Email : bassil@iro.umontreal.ca

* CIRANO and Département IRO, Université de Montréal. Email: benyouce@ iro.umontreal.ca

$\S$ CIRANO and Zühlke Engineering AG, Wiesenstrasse 10a,CH-8952 Schlieren, Switzerland. Email: ruk@zuehlke.com

${ }^{* *}$ CIRANO and Département IRO, Université de Montréal. Email: kropf @iro.umontreal.ca
} 


\section{Introduction}

Sourcing is defined by a set of steps related to the procurement of products/suppliers [14]. The main aspects of these steps can be summarized as follows:

- Identification: Identify requirements across divisions, develop RFI/RFP/RFQ (Request for Information, Proposal, Quotation), identify existing suppliers, and identify the procurement strategy.

- Evaluation: Conduct product category analysis, evaluate market dynamics (e.g., economic fluctuations of the market), and identify new suppliers.

- Negotiation: Conduct negotiations, and evaluate supplier proposals based on total cost, and possibly on other parameters.

- Configuration: Review and align negotiations across the supply chain.

Negotiation is of utmost importance in the context of sourcing; furthermore, it is required for effective support of B2B interactions. Many negotiation types are practiced in B2B markets, some of which are described in [14]. Among them, the multivariable negotiation is based on multiple parameters beyond just price, but including quality, delivery, warranty, and financial terms. The multistage negotiation consists of an RFI, an RFP, and an RFQ. In this type of negotiation, the buyer creates online requests for bids, the suppliers bid online, and then the buyer analyzes the bids [2]. Interactions between buyer and supplier are referred to as a multi-threaded negotiation. Furthermore, the finalization of purchases is not made without due consideration of availability/cost of services required to deliver these products. This latter negotiation is known as a synchronous supply chain negotiation.

Sourcing - or in a more specific way, e-sourcing (e.g., Web-based technology supporting the four steps stated before) - is an interesting framework that provides opportunities for procurement savings. Taking into account the number of companies that have been highly successful in achieving benefits through B2B sourcing [2], we chose to consider a sourcing application as our running example throughout the paper.

The "importing package" example described below stems from the area of transportation. In fact, importing goods is a quite complex procedure in which a buying company is involved in a number of activities/services such as the purchase of the goods, the shipment (we will also use the term "transportation" sometimes in this paper), the insurance, and the forwarding. These services are obviously interrelated and hence, we can imagine a combined negotiation $(\mathrm{CN})$ model as described in [4] to address this application. Furthermore, many constraints exist as well, which can also be encompassed by the $\mathrm{CN}$ model. Here are some of the constraints that are likely to be involved: the maximum price the buying company is willing to pay for the goods (e.g., unit price), the quantity needed, the payment terms (e.g., letter of credit, cash against documents, a certain percentage in advance, and the remaining percentage on delivery), the delivery date, the preferences for form of the goods (e.g., in bulk, packed). Regarding this latter aspect, we can imagine for instance the importation of cement that could be done in bulk or in bags. With regard to the shipping service, which may include inter-modal transportation, a number of scenarios are possible, and an obvious constraint is to agree upon specific conditions. The supplier can cover the freight shipment and insurance from warehouse of origin to warehouse of destination. Another alternative is to let the buyer cover all charges. In this latter scenario, a constraint is for instance to find a truck with a suitable arrival (resp. departure) time to port of shipment (resp. from port of destination), taking into account the vessel loading (resp. unloading) time. The buying company could have preferences for specific sea/surface shipping companies. It may also specify the maximum amount to be spent for each shipment phase, as well as the total amount for the whole shipping. As for the insurance, the buying company could also have some restrictions regarding the insurance companies, the kind of insurance, the price to pay, etc. Dependencies may exist between items. Indeed, a special kind of insurance could be preferred while a specific form of goods is considered.

Suppose that the complementary (i.e., cannot have one without the other) goods and services discussed above are negotiable (keeping in mind that the B2B sourcing techniques RFP and RFQ presented above, are negotiation types), and that the buying company chooses to engage in different negotiations for the goods and services, trying to make the best deal with respect to its interests. The different negotiations are usually carried out on different negotiation servers. Hence, they are independent of each other from the point of view of the negotiation servers. Suppose also that the negotiations practiced on each single server can be of different type (i.e., obey to different rules).

The need for a CN support system (CNSS) to solve a $\mathrm{CN}$ has already been motivated within several papers [4, 5]. Unfortunately, this solution is heavily based on a static Workflow Management System (WfMS). At the moment, there are more than two hundred WfMSs commercially available. A list of some systems is provided in [16]. A WfMS can be defined as a software that manages a workflow (Wf) efficiently by tracking and controlling its execution. It supports the definition, the execution and the monitoring of a Wf. The static aspect of such systems comes from the fact that the system does not provide functionalities allowing the user to change the Wf instance during execution (e.g., by inserting a new task, by deleting a task already here).

However, the key to make $\mathrm{CN}$ support more effective is to ensure that the buying company is working with WfMSs that are flexible enough during run-time, to accommodate 
the various internal (coming from the buying company) or external (coming from the supplier and/or the service companies, etc.) contingencies and/or obstacles that can appear.

Indeed, while negotiating, the supplier, the forwarding agent or even the shipping company can make a new offer that might interest the buying company, requiring this latter to review (e.g., move, delete, update attributes) one or multiple negotiation tasks already planned within the Wf model. If a strike reduces the supplier's activities, the buying company may choose for instance to give up the CN (i.e., cancel it altogether). Another alternative could be that the supplier or one of the service companies goes bankrupt. This could be covered by the insurance; however, it is not always cost-effective to do so, and hence the possibility to cancel the remaining negotiations becomes desirable. Finally, the buying company may change its mind concerning a specific attribute (e.g., the maximum price to pay for a specific item such as the transportation). It should be possible to re-set the pre-defined attributes related to each negotiation task; of course this should be done before launching the task.

The example above illustrates the important role of dynamism in e-negotiations, and especially in CNs. In this paper, we detail the need for and nature of dynamism as required by e-negotiations. Furthermore, we show to which extent state-of-the-art WfMS technology is able to support such dynamism, and we outline how systems should be extended to cope with this need.

Section 2 of this paper addresses process modeling in general and discusses the modeling of our "importing package" using a static WfMS. In Section 3, we discuss dynamism, first by identifying a number of dynamic scenarios in our $\mathrm{CN}$ example; then by demonstrating that ADEPT [13] - a WfMS supporting dynamism - is fit to cope to some extent, with dynamism in $\mathrm{CN}$ field; and finally by reviewing the Wf Reference Model, proposing a certain support for dynamism. Section 4 briefly discusses related work, and Section 5 concludes the paper.

\section{Modeling CNs}

\subsection{Process Modeling}

The use of CONSENSUS to support the user in conducting a $\mathrm{CN}$ has already been discussed in [4]. The system includes a WfMS to model the sequencing of the negotiations (represented as tasks) as well as the dependencies between them. It also allows to specify the different attributes (e.g., the maximum price to pay, the delivery date, etc.) related to each negotiation. The modeling phase (i.e., build-time phase) within CONSENSUS ensures to conduct the $\mathrm{CN}$ according to a well-thought plan. However, the enactment phase as it is implemented now, allows running the $\mathrm{CN}$, and hence the Wf instance, in a static manner, only. The limitations related to this approach will be discussed later in this paper.

Let us consider and discuss in this section the conceptual modeling in general. In fact, a model is an abstract representation of reality that excludes much of the world's infinite detail. Curtis et al. [7] specify that a model reduces the complexity of understanding or interacting with a phenomenon by eliminating the detail that does not influence its relevant behavior. However, many essential forms of information must be kept to adequately describe a model. A number of goals for (process) models are discussed in [7], and range from comprehensibility to enactability taking into account the automation of execution.

To the extent that automation is involved, process modeling becomes a vital issue in redesigning work and allocating responsibilities between humans and computers. A $\mathrm{CN}$ is indeed a complex process, and modeling gives a visual representation, which is easily understandable by humans, and identifies and formalizes all the necessary items of the CN. This may be helpful in a prospective evolution or modification of the current negotiation items, their sequencing and the dependencies between them. Modeling the $\mathrm{CN}$ also incites to reason about its variables and attributes. Further details about modeling, and CN modeling issues can be found in [5].

\subsection{Modeling our CN Example using WLPI}

WLPI (WebLogic Process Integrator) is a WfMS from BEA systems [3]. The Studio unit of WLPI is a client application that we used to model our running example. The CN model is created using a graphical tool integrated within the Studio unit. This model is stored in the WLPI database, and the Studio unit monitors its execution. A Worklist unit is another client application used to create and start instances of the CN model. WLPI is considered a static WfMS since it does not provide any dynamism during execution.

Figure 1 shows our running example created using WLPI Studio. Tasks are the core process activities of a Wf, and they evolve through various states (created, activated, executed, and marked done) as the Wf progresses.

In our example, the buying company has to take a decision regarding the number of negotiations that should be launched for the purchase of the goods. These tasks could be initiated at the same time, but only one deal should be stroke. The next step will be to start negotiations for the shipment services. We choose to begin by negotiating the sea shipment, and then the two surface shipments (from warehouse of origin to port of shipment, and from port of destination to warehouse of destination). The reason why the sea shipment is negotiated first is that surface transportation is usually more flexible and available. It will hence be easier to schedule the truck arrival (resp. departure) time to port of shipment (resp. from port of destination) with respect to the vessel loading (resp. unloading) time 
(than to do it in the opposite way). The insurance and the forwarding negotiations are planned in sequence as the last two items of our model. (For the sequencing, see Figure 1.)

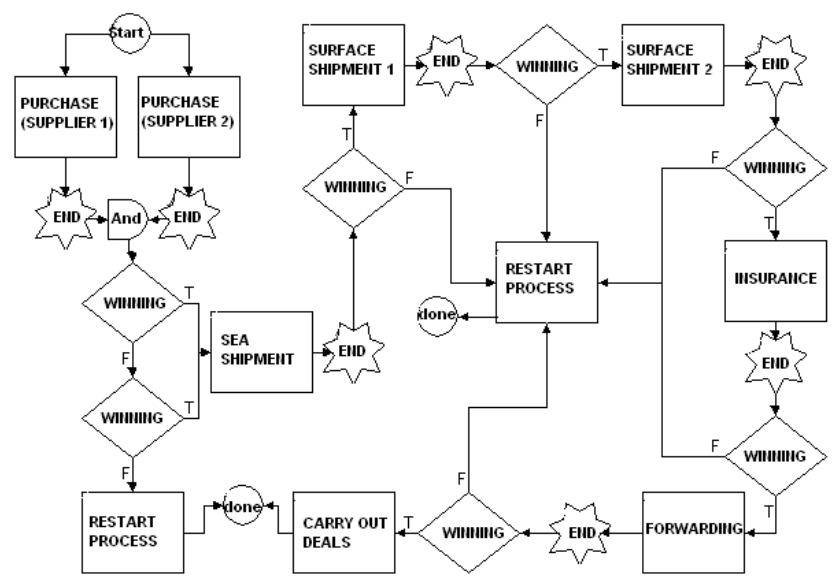

Figure 1. Wf model of the "importing package" in WLPI.

When we fail to make a deal on an item, after concluding deals on other complementary items, we talk of "exposure". To avoid exposure, we would have to restart the whole process ("Restart Process" task in Figure 1) by renegotiating some (or all) of the attributes of the deals already made. For instance, if we fail to find suitable transportation for a given date (fixed in a previous deal), then we could go back and re-discuss the delivery date with the supplier. In the worst case, this procedure could lead us to breaking our commitments.

A dynamic Wf can offer a better solution in such a case. Indeed, instead of restarting the whole process, a new negotiation could be launched for transportation with another shipping company, by inserting this new task into the Wf instance while it continues to run.

The "Restart Process" task is one of the ways that we can use to remedy the lack of flexibility during run-time. In the next section, we present some other scenarios highlighting dynamism, and we try to address one of them using a dynamic WfMS (ADEPT).

\section{Addressing Dynamism}

\subsection{Dynamic Aspects in our CN Example}

Although it is widely recognized that WfMSs should provide flexibility, most of today's systems unfortunately have problems dealing with changes. However, new offers, contingencies, and obstacles that can appear during negotiation, may require modifications of the $\mathrm{Wf}$ instance.

Indeed, taking into account our example, an obvious dynamic change could derive immediately after negotiating the purchase of the goods. The supplier can offer for instance, to cover the freight shipment and insurance from warehouse of origin to warehouse of destination. The buying company could be interested in this offer, and hence decides not to engage in any of the following steps of the $\mathrm{CN}$ (i.e., transportation, insurance, forwarding). It should be possible to the buying company to remove all these steps from the instance of the Wf during run-time.

Obviously, a similar offer could also come from the forwarding agent. In this case, the buying company might find it interesting to engage in the negotiation with the forwarding agent in parallel with the transportation, thus the possibility to move (or to delete and to re-insert) the forwarding task right after the purchase of goods tasks is wished for. In case the negotiation with the forwarding agent succeeds (covering the freight shipment and insurance), a next step would be to delete all the negotiation tasks related to transportation and insurance.

Among other possibilities, the two dynamic scenarios described above could occur in a real-world importing process. Hence, it would be advantageous for a $\mathrm{CN}$ to allow on-the-fly changes (i.e., make changes while an instance of the Wf model is running).

\subsection{Dynamic Modifications using ADEPT}

ADEPT (Application Development based on Encapsulated pre-modeled Process Templates) is a WfMS from the University of Ulm [13]. It offers support for some dynamic changes, giving the possibility, at run-time, to deviate from the pre-modeled task sequence. The ADEPT Wf-Editor is a build-time client application for modeling tasks. It features a graphical tool that allows visualizing and adjusting the attributes related to the different tasks. However, links between tasks are defined manually as instructions within the specific-format file generated by the Wf-Editor. As with WLPI, the Wf model is stored in a database. The ADEPT Client monitors the execution of a model, allowing the user to intervene via the Worklist unit, by inserting or deleting a task to the instance already created and launched. The task to insert should exist in one of the instances already created (even the ones related to a different Wf model). It is not permitted to define/model a new task during run-time. Moreover, a certain number of constraints must be satisfied before proceeding to the modification steps, and no modification is allowed while a specific task is running (i.e., its state is "running").

We used ADEPT to model and run the "importing package", in order to address the issue of dynamism in CNs. Two main criteria were applied to retain this system among the few promising prototypes (see Section 4) that have recently emerged to deal with flexibility. Indeed, the first criterion is related to the interest granted to this system within the literature $[8,16]$, whereas the second criterion concerns its availability.

Figure 2 shows our running example within the ADEPT Client (Monitoring unit), based on the second scenario described in Section 3.1. Boxes in Figure 2(a) represent 
tasks that correspond to the different negotiations of the "importing package" as shown in Figure 1. A "start" node (S), an "end" node (E), and a "carry out deals" task (node C) are added. Two "empty" nodes are used for the andsplit and the and-join of the "purchase (supplier 1 and 2)" tasks (nodes S1 and S2). Inserting a task to the current instance requires synchronization with tasks that must be completed before and after the inserted one. In our example, the "forwarding" task (node F) should be activated after the two "purchase (supplier 1 and 2)" tasks, and obviously before the "carry out deals" task. The edge from node S1 (resp. S2) to node F, and the one from node F to node $\mathrm{C}$ in Figure 2(b) show the synchronization. Figure 2(c) depicts the case where the negotiation with the forwarding agent succeeds; all the remaining negotiations related to transportation (nodes T1, T2, and T3) and insurance (node I) are deleted (even the already activated task "sea shipment" - node T1), going straight to the "carry out deals" task. Note that the two tasks "forwarding" and "sea shipment" are activated in parallel; however, the "forwarding" task is completed first.

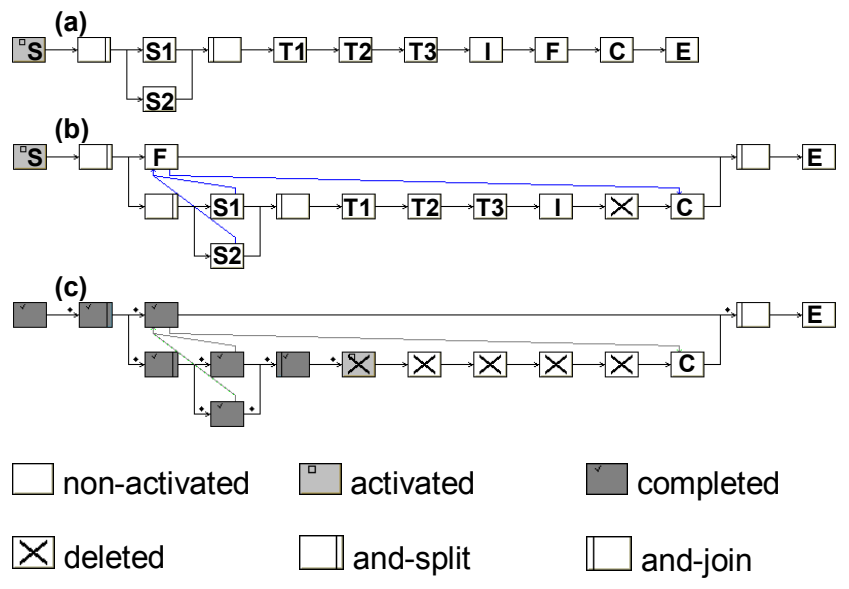

Figure 2. "Importing package" during run-time in ADEPT. Instance state (a) after creation, (b) after moving (i.e., deleting and inserting) task F, (c) after deleting tasks: T1, T2, T3, and I.

From our experience with ADEPT, we realized that defining decisions makes our model less flexible to deal with dynamic modifications during run-time, since it is not easy to adjust a moved ${ }^{2}$ task (e.g., "forwarding") with its corresponding decision branch. Consequently, we chose to model our $\mathrm{CN}$ example without decision branches letting the user decide manually whether to go for the next negotiation in the sequence, to delete specific task(s), or even to insert new one(s); obviously this should take into account the negotiation results (e.g., deal or not, fixed delivery date) of the previously completed task. Furthermore, allowing automatic launching of tasks (as a result of a deci-

\footnotetext{
${ }^{2}$ We talk of moving a task when we delete a specific task, and insert it in a different place.
}

sion branch) reduces the opportunities for user intervention, since no modification is allowed while a certain task is running. The previous argumentations suggest that in order to offer a more flexible model (i.e., model that supports more dynamic modifications), we need to define less automatic tasks, avoiding for instance decision branches.

In the case of dependent attributes between tasks (e.g., an item needs the result of a predecessor item as input), ADEPT does not allow to delete the producing task. This is perfectly coherent. However, since it is not allowed to modify attributes - mainly to delete the pre-affected attributes to the consuming task - it makes, once again, our model less flexible regarding deletion. Although we did not experiment this with our running example, we are pretty sure that dependent attributes may easily appear in CNs. We think that a possible solution could be to permit dynamic modification of attributes.

\subsection{Workflow Reference Model and Dynamism}

The Wf Management Coalition (WfMC) [15] has developed an overall model for Wf systems. This model, called the Wf Reference Model, identifies the characteristics, terminology, and components of WfMSs, thus enabling individual specifications to be developed within its context. At the highest level, all WfMSs may be characterized as providing support in three functional areas [17]: (1) the build-time functions, concerned with defining, and possibly modeling the Wf process and its constituent activities; (2) the run-time control functions, concerned with managing the Wf processes in an operational environment and sequencing the various activities to be handled as part of each process; and (3) the run-time interactions with human users and IT applications for processing the various activity steps. The WfMC specifies that some WfMSs may allow dynamic alterations to process definitions (an instance of the original model) from the run-time operational environment [17]. Since the run-time operational environment is involved within the second and third functional areas, a WfMS supporting dynamic alterations could be seen, from our point of view, as a system that extends these two functional areas by a set of run-time "process modification functions" that allow the user to modify instances of the original model with the minimum effort.

At a lower level, the architecture of the Wf Reference Model identifies five interfaces (see legend in Figure 3) [17]. These interfaces are related to the Wf enactment service, and they are supported by a set of API calls (WAPI). Many operations are identified across the five interface areas. These operations are gathered within a number of groups represented by the 13 ellipses in Figure 3.

The "Interface 2" (Workflow Client Applications) is defined as the one supporting interactions with user interface desktop functions. Consequently, a possibility to allow dynamism in a WfMS is to add to this interface a set 
of operations for the creation, the retrieval, and the deletion of a particular object within a Wf definition, and even the retrieval, the setting, and the deletion of a particular object attribute. These operations are already covered by the current WAPI, and they are gathered within the "Workflow definition object operations" group [17]. Figure 4 reflects the possible group addition (gray ellipse) to "Interface 2 " to enable dynamism.
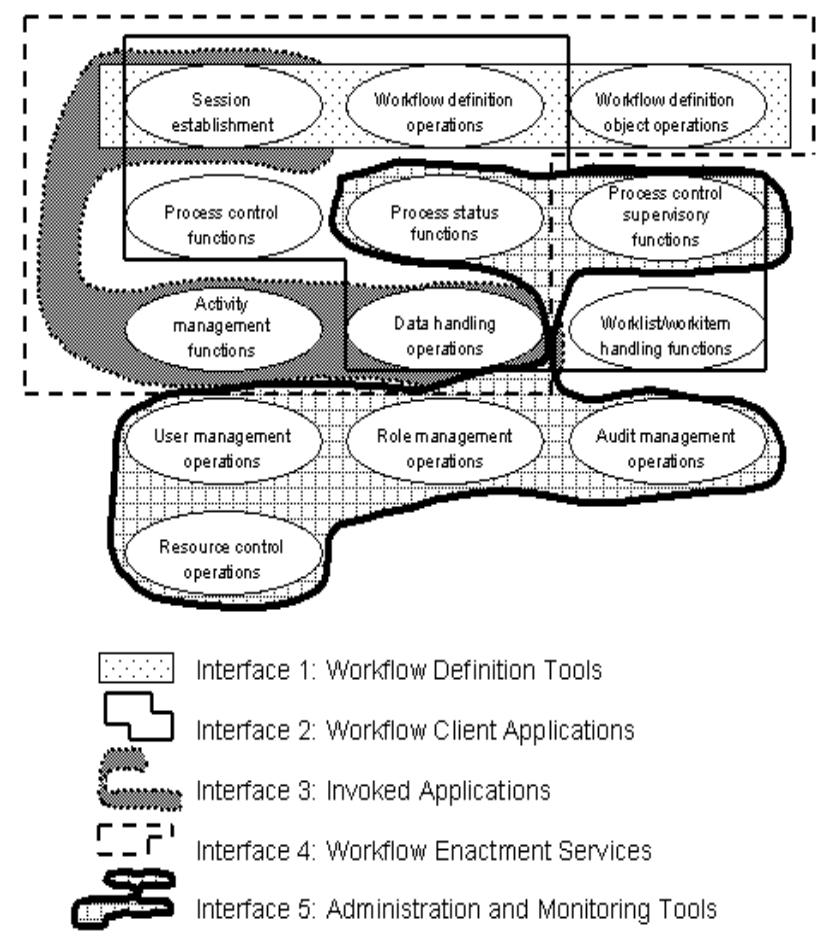

Figure 3. Groups of operations distributed within the five interfaces of the Wf Reference Model

(a)

(b)
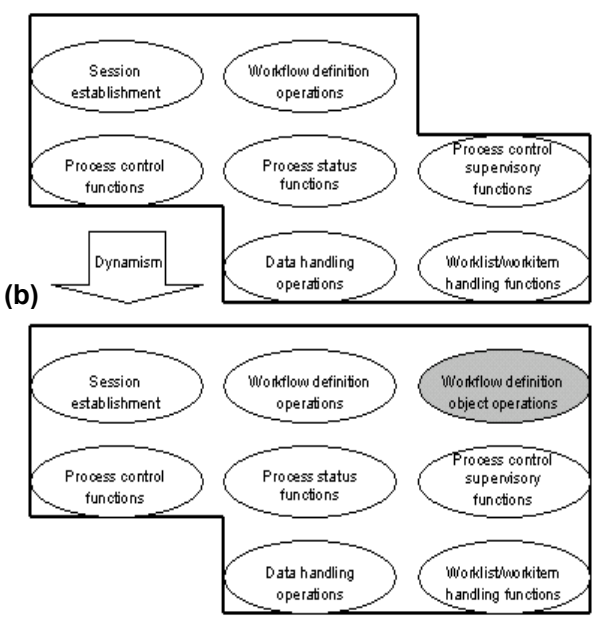

Figure 4. Groups of operations related to "Interface 2", (a) as defined by the Wf Reference Model, (b) taking into account the dynamism aspect in WfMSs

\section{Related Work}

CNs are a novel negotiation type [4], and CONSENSUS was probably the first Wf-based system to support them. Dynamism has widely been recognized as an important feature of WfMSs in general, but in our context, the inability to deal with it limits the benefits of the CONSENSUS approach.

Currently, many researchers are working on problems related to dynamic Wfs $[1,8,11,13,16]$, however few commercial systems provide support for this kind of Wfs $[10,12]$.

The first work in the literature that motivated the issues of dynamic Wf change was [9]. Ellis et al. showed that change to Wf instances could be accomplished dynamically without aborting or restarting tasks already completed or in progress.

Recently, Wf prototype efforts have emerged to address flexibility in Wf systems. These prototypes include ADEPT [13] (already discussed in Section 3.2) and Milano [1]. The flexibility of Milano is based on a net-theoretical modeling framework allowing three possible categories of change (parallelization, sequentialization, and swapping of tasks). Ellis and Keddara introduced rather a Modeling Language to support Dynamic Evolution within Wf Systems (ML-DEWS) [8]. Their framework handles various change modalities, change composition, ad hoc change, participatory change and exception.

As a final note concerning related work, we would like to highlight the fact that dynamism is an important aspect in numerous domains other than $\mathrm{CN}$, such as software engineering [6].

\section{Conclusion and Future Work}

In this paper, we mainly showed the need for dynamism in CNs. We began by motivating the use of Wf technology for the modeling part of a $\mathrm{CN}$. We then pointed to the lack of flexibility in static WfMS, and tried to address dynamism by way of a WfMS that supports dynamic modifications. Finally, we reviewed the Wf Reference Model recognizing the lack of support for dynamism in the current architecture, and proposing an extension for dynamic support within WfMSs.

As future work, firstly, we are looking at integrating ADEPT into the current prototype of CONSENSUS. This will lead to consider user intervention in the "Workflow Monitoring and Control Tool" of the current CONSENSUS architecture [4]. As a second direction, a wish list of dynamic modifications required for CNs should be produced. We need to be aware of the shortcomings and limitations of current dynamic WfMSs in respect to the modeling and running of CNs. These limitations should give us a valuable input for future versions of current dynamic systems. 


\section{References}

[1] Agostini, A., and De Michelis, G., Improving Flexibility of Workflow Management Systems. In W. van der Aalst et al. (Ed.): Business Process Management, Lectures Notes in Computer Science, LNCS 1806, 218-234. Spring-Verlag, Berlin, Heidelberg, 2000.

[2] B2B Sourcing a Quick Hit, 2000. Sourcing On an Online Exchange. On-line at $<\mathrm{http} / /$ www.ebizchronicle.com /backgrounders/november/b2bsourcing.htm>.

[3] BEA Systems WLPI. On-line at <http://www.beasys.com /products/weblogic/integration/index.shtml $>$.

[4] Benyoucef, M., Alj, H., Vézeau, M., and Keller, R. K., Combined Negotiations in E-Commerce: Concepts, and Architecture. Electronic Commerce Research Journal, 1(3):277-299, July 2001. Special Issue in Theory and Application of Electronic Market Design. Baltzer Science Publishers.

[5] Benyoucef, M., Bassil, S., and Keller, R. K., Workflow Modeling of Combined Negotiations in E-Commerce. In Proceedings of the Fourth International Conference on Electronic Commerce Research (ICECR-4), 348-359, Dallas, Texas, November 2001.

[6] Cugola, G., Tolerating Deviations in Process Support Systems via Flexible Enactment of Process Models. IEEE Transactions on Software Engineering, 24(11), 1998.

[7] Curtis, B., Kellner, M. I., and Oliver, J., Process Modeling. Communications of the ACM, 35(9):75-90, September 1992.

[8] Ellis, C. A., and Keddara, K., A Workflow Change Is a Workflow. In W. van der Aalst et al. (Ed.): Business Process Management, LNCS 1806, 201-217. Spring-Verlag, Berlin, Heidelberg, 2000.

[9] Ellis, C. A., Keddara, K., and Rozenberg, G., Dynamic Change within Workflow Systems. In Proceedings of the Conference on Organizational Computing Systems. ACM Press, 10-21, New York, 1995.

[10] FileNet. Ensemble User Guide. FileNet Corp., Costa Mesa, California, 1998.

[11] Heinl, P., Horn, S., Jablonski, S., Neeb, J., Stein, K., and Teschke, M., A Comprehensive Approach to Flexibility in Workflow Management Systems. In Work Activities Coordination and Collaboration (WACC'99), 79-88, San Francisco, California, February 1999. New York: ACM Press, 1999.

[12] InConcert. InConcert Process Designer Guide. InConcert, Inc., Cambridge, Massachusetts, 1997.

[13] Reichert, M., and Dadam, P., ADEPTflex: Supporting Dynamic Changes of Workflow without Losing Control. Journal of Intelligent Information Systems, 10(2): 93-129, 1998.

[14] Sourcing: The key to competitive advantage. Powerpoint Presentation from Aberdeen Group, 2000. On-line at $<\mathrm{http} / /$ www.aberdeen.com/>.

[15] The Workflow Management Coalition. On-line at $<$ http://www.wfmc.org/>.

[16] van der Aalst, W., and van Hee, K., Workflow Management: Models, Methods, and Systems. The MIT Press. 368 pp., 2002. ISBN 0-262-01189-1.

[17] Workflow Management Coalition, The Workflow Reference Model. WFMC-TC-1003, January 1995, 1.1. On-line at $<$ http://www.wfmc.org/standards/docs/tc003v11.pdf $>$. 


\section{Liste des publications au CIRANO*}

Série Scientifique / Scientific Series (ISSN 1198-8177)

2002s-56 Addressing Dynamism in E-negotiations by Workflow Management Systems / Sarita Bassil, Morad Benyoucef, Rudolf K. Keller et Peter Kropf

2002s-55 Experimenting with Gnutella CommunitiesJean Vaucher, Gilbert Babin, Peter Kropf, Thierry Jouve

2002s-54 Incentives? The Effect of Profit Sharing Plans Offered by Previous Employers on Current Wages / Daniel Parent

2002s-53 Multi-Task Learning For Option Pricing / J. Ghosn et Y. Bengio

2002s-52 Input Decay: Simple and Effective Soft Variable Selection / N. Chapados et Y.

Bengio

2002s-51 On Out-of-Sample Statistics for Time-Series / F. Gingras, Y. Bengio et C. Nadeau

2002s-50 Forecasting Non-Stationary Volatility with Hyper-Parameters / Y. Bengio et C. Dugas

2002s-49 Cost Functions and Model Combination for VaR-based Asset Allocation using Neural Networks / N. Chapados et Y. Bengio

2002s-48 Experiments on the Application of IOHMMs to Model Financial Returns Series / Y. Bengio, V.-P. Lauzon et R. Ducharme

2002s-47 Valorisation d'Options par Optimisation du Sharpe Ratio / Y. Bengio, R. Ducharme, O. Bardou et N. Chapados

2002s-46 Incorporating Second-Order Functional Knowledge for Better Option Pricing / C. Dugas, Y. Bengio, F. Bélisle, C. Nadeau et R. Garcia

2002s-45 Étude du Biais dans le Prix des Options / C. Dugas et Y. Bengio

2002s-44 Régularisation du Prix des Options : Stacking / O. Bardou et Y. Bengio

2002s-43 Monotonicity and Bounds for Cost Shares under the Path Serial Rule / Michel Truchon et Cyril Téjédo

2002s-42 Maximal Decompositions of Cost Games into Specific and Joint Costs / Michel Moreaux et Michel Truchon

2002s-41 Maximum Likelihood and the Bootstrap for Nonlinear Dynamic Models / Sílvia Gonçalves, Halbert White

2002s-40 Selective Penalization Of Polluters: An Inf-Convolution Approach / Ngo Van Long et Antoine Soubeyran

2002s-39 On the Mediational Role of Feelings of Self-Determination in the Workplace: Further Evidence and Generalization / Marc R. Blais et Nathalie M. Brière

2002s-38 The Interaction Between Global Task Motivation and the Motivational Function of Events on Self-Regulation: Is Sauce for the Goose, Sauce for the Gander? / Marc R. Blais et Ursula Hess

\footnotetext{
* Consultez la liste complète des publications du CIRANO et les publications elles-mêmes sur notre site Internet :
} 
2002s-37 Static Versus Dynamic Structural Models of Depression: The Case of the CES-D / Andrea S. Riddle, Marc R. Blais et Ursula Hess

2002s-36 A Multi-Group Investigation of the CES-D's Measurement Structure Across Adolescents, Young Adults and Middle-Aged Adults / Andrea S. Riddle, Marc R. Blais et Ursula Hess

2002s-35 Comparative Advantage, Learning, and Sectoral Wage Determination / Robert Gibbons, Lawrence F. Katz, Thomas Lemieux et Daniel Parent

2002s-34 European Economic Integration and the Labour Compact, 1850-1913 / Michael Huberman et Wayne Lewchuk

2002s-33 Which Volatility Model for Option Valuation? / Peter Christoffersen et Kris Jacobs

2002s-32 Production Technology, Information Technology, and Vertical Integration under Asymmetric Information / Gamal Atallah

2002s-31 Dynamique Motivationnelle de l'Épuisement et du Bien-être chez des Enseignants Africains / Manon Levesque, Marc R. Blais, Ursula Hess

2002s-30 Motivation, Comportements Organisationnels Discrétionnaires et Bien-être en Milieu Africain : Quand le Devoir Oblige / Manon Levesque, Marc R. Blais et Ursula Hess

2002s-29 Tax Incentives and Fertility in Canada: Permanent vs. Transitory Effects / Daniel Parent et Ling Wang

2002s-28 The Causal Effect of High School Employment on Educational Attainment in Canada / Daniel Parent

2002s-27 Employer-Supported Training in Canada and Its Impact on Mobility and Wages / Daniel Parent

2002s-26 Restructuring and Economic Performance: The Experience of the Tunisian Economy / Sofiane Ghali and Pierre Mohnen

2002s-25 What Type of Enterprise Forges Close Links With Universities and Government Labs? Evidence From CIS 2 / Pierre Mohnen et Cathy Hoareau

2002s-24 Environmental Performance of Canadian Pulp and Paper Plants : Why Some Do Well and Others Do Not? / Julie Doonan, Paul Lanoie et Benoit Laplante

2002s-23 A Rule-driven Approach for Defining the Behavior of Negotiating Software Agents / Morad Benyoucef, Hakim Alj, Kim Levy et Rudolf K. Keller

2002s-22 Occupational Gender Segregation and Women's Wages in Canada: An Historical Perspective / Nicole M. Fortin et Michael Huberman

2002s-21 Information Content of Volatility Forecasts at Medium-term Horizons / John W. Galbraith et Turgut Kisinbay

2002s-20 Earnings Dispersion, Risk Aversion and Education / Christian Belzil et Jörgen Hansen

2002s-19 Unobserved Ability and the Return to Schooling / Christian Belzil et Jörgen Hansen

2002s-18 Auditing Policies and Information Systems in Principal-Agent Analysis / MarieCécile Fagart et Bernard Sinclair-Desgagné

2002s-17 The Choice of Instruments for Environmental Policy: Liability or Regulation? / Marcel Boyer, Donatella Porrini

2002s-16 Asymmetric Information and Product Differentiation / Marcel Boyer, Philippe Mahenc et Michel Moreaux 